\title{
Privacidade e o direito de morrer com dignidade
}

\author{
Privacy and the right to die dignity
}

\author{
Riva Sobrado de Freitas ${ }^{*}$ \\ Narciso Leandro Xavier Baez ${ }^{* *}$
}

\section{Resumo}

O trabalho intitulado "Privacidade e o direito de morrer com dignidade" nos levou, primeiramente, à pesquisa sobre os diferentes procedimentos de morte que pudessem conferir dignidade pessoal ao paciente. Entretanto, em face da pluralidade destes, entendemos ser fundamental focar nossa discussão sobre a privacidade decisória e sua tutela constitucional, para a coleta de subsídios necessários a uma reflexão crítica sobre eutanásia, ortotanásia, distanásia etc. Após nossos estudos, verificamos a importância da existência de simetria nas relações entre médicos e pacientes para a tomada de uma decisão responsável quanto ao procedimento de morte. Concluímos também ser necessária a legalização da eutanásia como forma de estabelecer parâmetros claros de comportamento para profissionais da medicina, hospitais, sistemas de saúde (privados e públicos) e pacientes, de modo a evitar procedimentos como "morte roubada" ou distanásia, que não contam com a anuência do doente.

Palavras-chave: Privacidade decisória. Direito ao corpo. Eutanásia. Distanásia. Ortotanásia.

* Coordenadora, pesquisadora e professora do Programa de Pós-Graduação em Direito da UNOESC. Professora assistente-doutora aposentada da Universidade Estadual Paulista Júlio de Mesquita Filho - UNESP. Pós-doutora em Direito pela Universidade de Coimbra. Doutora e mestre em Direito pela PUC/SP. Chapecó- SC - Brasil. Email: rivafreit@ig.com.br

** Coordenador acadêmico científico, professor e pesquisador do Programa de Pesquisa, Extensão e Pós-Graduação em Direito e do Centro de Excelência em Direito da Universidade do Oeste de Santa Catarina. Pós-doutorando em Mecanismos de Efetividade dos Direitos Humanos Fundamentais na Universidade Federal de Santa Catarina. Doutor em Direitos Fundamentais e Novos Direitos, com estágio de doutorado (bolsa CAPES) no Center for Civil and Human Rights da University of Notre Dame, Indiana, Estados Unidos. Mestre em Direito Público. Especialista em Processo Civil. Graduado em Ciências Jurídicas e Sociais pela Pontifícia Universidade Católica do Rio Grande do Sul. Juiz federal da Quarta Região (Brasil) desde 1996. Chapecó- SC - Brasil. Email:narciso.baez@gmail.com 


\title{
Abstract
}

The article entitled: Privacy and the Right to Die with Dignity, led us to research on first time the differents procedures of death that could give personal dignity to the patient. However, in face the plurality of procedures, we understand fundamental to keep our focus in the discussion about on Privacy Decisional and its constitutional protection, with the purpose of collect the necessary subsidies to a critical reflection on the procedures available of death: euthanasia, orthothanasia, disthanasia, beyond others. After our studies, we verify the importance of symmetry in the relationship between doctors and patients for taking a responsible decision as to the procedure of death. We also conclude, by the necessity of legalizing euthanasia as a way to establish clear benchmarks for the behavior of medical professionals, hospitals, health care system (private and public) and patients, in order to avoid procedures such as "stolen death" or disthanasia without the consent of the patient.

Keywords: Privacy decisional. Right to the body. Euthanasia. Disthanasia. Orthothanasia.

\section{Introdução}

\author{
Não tenho medo da morte, \\ mas medo de morrer, sim \\ a morte é depois de mim \\ mas quem vai morrer sou eu \\ o derradeiro ato meu \\ e eu terei que estar presente \\ assim como um presidente \\ dando posse ao sucessor \\ terei que morrer vivendo \\ sabendo que já me vou...
}

Não tenho medo da Morte, Gilberto Gil

Nossa pesquisa tem como problema central a evolução do direito à privacidade, constatando que ele abandonou os contornos 
liberais de uma simples blindagem oponível erga omnes aos moldes do "individualismo possessivo" de MacPherson (1979) para assumir dimensões mais compatíveis com a diversidade e o respeito à alteridade, de modo a promover o empoderamento do corpo (embodiment), essencial à dignidade pessoal, consoante as exigências contemporâneas. Daí a necessidade de se colocar à prova essas novas premissas, no tocante a situações limítrofes, em que morrer com dignidade pode ser uma escolha do indivíduo.

É importante salientar que este estudo não tem como objetivo central esgotar o debate sobre as diversas possibilidades de morte digna, mas apenas refletir sobre a importância do empoderamento do corpo e da dignidade pessoal para a escolha de qualquer uma delas.

Dessa forma, em um primeiro momento, nossa preocupação com o tema nos levou a pesquisar os diferentes procedimentos para a morte que pudessem conferir alguma dignidade pessoal, já que se trata de um momento significativo na vida de cada um. Entretanto, observando a pluralidade de caminhos disponíveis, entendemos a importância de se retomar a discussão sobre a privacidade, notadamente a privacidade decisória, em face da sua relevância para o controle e disponibilidade do próprio corpo, sem os quais a dignidade pessoal ficaria comprometida.

Assim, procuramos redescrever a privacidade e sua tutela constitucional, conferindo a ambas um substrato conceitual mais apropriado às necessidades contemporâneas a partir das informações críticas que tendem a identificá-las com os demais direitos individuais de tradição liberal e conteúdo abstrato, os quais não atendem às necessidades de tutela concreta do indivíduo.

Posteriormente, ocupamo-nos com a apresentação e descrição dos diferentes procedimentos disponíveis para a morte, buscando problematizá-los e, acima de tudo, ressaltar a importância do respeito à privacidade para a garantia da dignidade pessoal intransferível. Para tanto, identificamos como necessária a simetria na relação entre médicos e pacientes, elemento capaz de promover uma decisão responsável. 


\section{Considerações sobre o direito à privacidade em sua dimensão autonomia decisória: a proposta de uma reavaliação de seu conteúdo}

Numa tentativa de retomar o direito à privacidade, procurando reavaliar seu conteúdo com vistas à construção de um novo significado, observamos que, por um lado, a privacidade pessoal, constitucionalmente protegida, tem representado um avanço indispensável a qualquer concepção moderna de liberdade; por outro, tem sido objeto de inúmeras críticas.

Alvo de diferentes acusações e desconfianças, o direito à privacidade é apontado, sobretudo, por reforçar um modelo ideológico liberal, fundado na dicotomia público/privado. Interpretados consoante essa afirmação, os direitos à privacidade teriam como meta central a proteção dos indivíduos contra o Estado, o que reforçaria ainda mais as tendências desagregadoras e atomizadoras da sociedade moderna (COHEN, 2012).

As críticas "comunitaristas" consideram a constitucionalização do direito à privacidade um retrocesso, na medida em que inviabiliza a afirmação dos valores comunitários e a solidariedade (COHEN, 2012).

Pelo que se pode observar, ambas as abordagens formulam críticas ao direito à privacidade tomando como base argumentos contrários à interpretação liberal desse direito, como se ela fosse a única possível.

Entretanto, antes de podermos levar a efeito algumas ponderações sobre as abordagens críticas ora apresentadas, seria oportuna a delimitação do conteúdo do direito à privacidade, pelo menos nas suas dimensões mais importantes, para que pudéssemos refletir a respeito.

Duas dimensões são preponderantes quando se trata da privacidade pessoal. A primeira consiste no direito de ser "deixado em paz". Essa possibilidade tutelada tornou-se extremamente importante, especialmente quando uma tecnologia já bastante desenvolvida torna a vida pessoal vulnerável e passível de ser devassada por motivos fúteis 
ou interesses escusos, e não apenas na intimidade do lar, mas também no que diz respeito às informações arquivadas nos diferentes bancos de dados. Naturalmente, as informações, quando cruzadas, sem que para tanto haja interesse público relevante, expõem e comprometem a integridade pessoal e física/emocional (BITTAR, 1989). Portanto, o "direito de ser deixado em paz" significa o direito de não sofrer intromissão ou vigilância sem motivo justo. É importante ressaltar que não se trata do reconhecimento de mais um direito individual em termos liberais. Não se busca a tutela de mais um valor abstrato, ideologicamente atribuído ao indivíduo "natural", mas a proteção individuada (YOUNG, 1990), concreta e real da intimidade de uma pessoa, atributo que a torna única e a identifica entre as demais. A violação dessa dimensão da privacidade, especialmente em face de uma tecnologia avançada e globalizada, poderá causar um dano irreparável à dignidade humana.

Embora seja extremamente significativa essa dimensão da privacidade, ela vem sendo pouco contestada. Entretanto, há outra dimensão, própria do direito à privacidade, que nos parece ser o alvo central das polêmicas atuais travadas por todos os que discutem os limites da autonomia decisória quanto ao próprio corpo. Trata-se da "privacidade decisória", do direito de não ser submetido ao controle indevido (regulações, inclusive) por parte de terceiros (COHEN, 2012).

A primeira dimensão apontada estaria referida na "privacidade informacional" (COHEN, 2012), ou seja, posse e disseminação de informações sobre a pessoa (indivíduos ou organizações privadas, assim como autoridades públicas). A segunda, objeto de inúmeras polêmicas, tocaria primordialmente na autonomia decisória quanto à "zona de intimidade", abrangendo a disponibilidade íntima (COHEN, 2012) para relações sexuais, casamentos, abortos, eutanásia etc.

Considerando esta última dimensão apresentada, observamos que as principais críticas sobre os direitos individuais em geral e, especificamente, sobre os direitos de privacidade referem-se, como já pontuamos, ao modelo liberal sociedade/Estado, o qual supostamente estaria sendo reforçado pela tutela da privacidade, na sua dimensão de "autonomia decisória". 
Essas abordagens críticas, constantemente levantadas pelos movimentos de gênero, pontuam a questão da igualdade, comprometida de forma recorrente nas relações liberais/iluministas.

Quando nos reportamos ao liberalismo inicial (Rousseau, Montesquieu), constatamos a sua correspondência ao momento marcado pela afirmação do segmento social burguês e imposição de toda a sua ideologia. Nesse sentido, a teoria do direito natural trouxe contribuições decisivas, na medida em que toma como base a existência de "regras naturais", supostamente perenes e essenciais à "natureza humana", para além de serem anteriores e independentes ao Estado (BOBBIO, 1992).

As revoluções liberais utilizaram-se desses argumentos "naturais" para derrubar governos absolutos e instaurar a ordem burguesa.

Em que pese a sedução de tais argumentos revolucionários, é forçoso afirmar que as "regras naturais" e os valores estabelecidos como próprios à "natureza humana" estavam repletos do conteúdo ideológico burguês e historicamente serviram à exclusão dos segmentos sociais subalternos e à dominação de gênero. Basta lembrarmo-nos que as relações sociedade/Estado liberal foram estabelecidas com base no voto "qualificado" apenas para homens proprietários e com determinado nível de conhecimento.

Certamente, as "regras naturais" destinaram o espaço privado às mulheres e conservaram a dimensão pública à convivência masculina. Nas relações domésticas, marcadas por valores patriarcais supostamente "naturais", às mulheres ficou reservado o status subalterno, comprometendo definitivamente a igualdade.

Entretanto, embora os argumentos de igualdade e gênero sejam irrefutáveis, quando apresentados em oposição aos direitos individuais liberais, o direito à privacidade pode e deve ser retomado sob ótica distinta. Ele, especialmente na sua dimensão decisória (autonomia decisória), designa o indivíduo como o centro de seu processo, não determinando de forma alguma uma escolha ética ou ideológica a ser 
seguida, mas apenas uma esfera de autodeterminação, dentro da qual deve exercer a sua identidade concreta, efetuando suas escolhas pelos próprios motivos, inclusive sem ter que justificá-los (COHEN, 2012). A respeito de direitos dessa natureza, Arendt (1998) explica que eles atribuem ao indivíduo uma "persona legal" que serve como "escudo protetor" para sua identidade pessoal.

A outra crítica recorrente, sobre a qual já nos referimos, também parte de considerações contrárias às formulações liberais, especialmente porque entende que a autonomia decisória, quando tutela o poder de autodeterminação, estaria a reforçar no indivíduo o seu desenraizamento, promovendo uma ruptura com as normas e valores comunitários e a quebra dos vínculos de solidariedade que o cercam.

Quando consideramos os direitos individuais, de corte liberal, próprios do individualismo burguês e das formações sociais forjadas a partir desse ideário, certamente percebemos que as relações sociedade/Estado se estabelecem a partir de indivíduos dissociados, cujas decisões políticas do Estado se originam da "vontade geral", nos moldes da democracia burguesa, baseada no "voto qualificado", como já mencionamos.

O que se percebe é que o indivíduo deslocado do todo social, através do voto censitário, tem como meta fundamental a realização de seu próprio bem-estar. Dessa forma, suas relações passam a ter como fundamento ético somente o cálculo dos próprios interesses. Assim, o indivíduo apartado da coletividade tende a valorizar unicamente a possibilidade de realização de suas potencialidades e de sua capacidade de possuir. Quanto mais realiza o seu bem-estar, mais possuirá e maior será seu valor enquanto indivíduo (MACPHERSON, 1979).

Essa qualidade, que se encontra na própria definição do indivíduo burguês, consoante Macpherson (1979, p. 250), traduz-se na: "Condição do indivíduo como sendo essencialmente o proprietário de sua pessoa e de suas próprias capacidades, nada devendo à sociedade por elas".

Sem dúvida, são merecedoras de crédito tais considerações. A coletividade, concebida como uma somatória de indivíduos, cada 
um a defender os seus interesses, significa a negação de qualquer possibilidade de existência de um todo social dotado de conceitos morais próprios e valores éticos definidos.

Nessa circunstância, a única identidade possível entre seus membros é a vocação para possuir, que se pretende inerente à "natureza humana".

Entretanto, apesar das críticas formuladas ao ideal voluntarista da pessoa, descrito por Macpherson (1979), não nos parece determinante subordinar o conceito de direito à privacidade, na sua dimensão de privacidade decisória, a uma concepção de indivíduo desenraizado, uma característica do paradigma liberal. Em verdade, o que se estaria buscando com essa tutela seria a proteção do núcleo de autonomia pessoal, quer contra as "normas comunitárias", que muitas vezes podem ser abusivas em relação à autonomia pessoal decisória, quer contra a própria vontade da maioria, muitas vezes desrespeitosa no quesito diversidade.

\section{A privacidade decisória mediada pelo corpo: o "embodiment" enquanto substrato crucial da identidade}

Quando nos reportamos à tutela dispensada aos atributos físicos e mentais, individualizadores do nosso ser pelo ordenamento jurídico, identificamos um grupo de direitos conexos, conhecidos como direitos de personalidade.

A teoria dos direitos de personalidade é recente e ainda não sedimentada, daí as divergências apontadas, sobretudo no tocante à sua generalidade e extensão (BITTAR, 1989).

Entretanto, como os direitos de personalidade tendem a alcançar dispositivos sobre o direito ao corpo, assim como sobre a privacidade, por serem essenciais à dignidade humana, pensamos haver pertinência em uma breve exposição sobre o tema.

Quando observamos a proteção dispensada pelo direito à personalidade, constatamos que este não se ocupa da sua definição 
nem da sua tutela direta. Ele busca normatizar a proteção dos atributos próprios à individualização de uma pessoa. Dessa forma, procura a tutela de aspectos íntimos do indivíduo - tomado em si mesmo ou como ente individualizado na sociedade - ou aspectos originados da sua interação ou projeção em sociedade (BITTAR, 1989).

Assim, teríamos entre os direitos de personalidade a tutela de atributos do corpo físico, como o direito ao corpo (ou a partes separadas do corpo), à voz, à imagem (retrato) etc. A proteção da esfera pessoal psíquica também estaria contemplada, alcançando os direitos ao segredo, de maneira geral, e o direito à intimidade e à privacidade, especificamente (BITTAR, 1989).

Os aspectos relativos à projeção em sociedade também compreenderiam os direitos de personalidade, alcançando a tutela da reputação ao direito do autor (BITTAR, 1989).

É importante ressaltar que esses direitos possuem uma dimensão que transita para além dos direitos individuais abstratos, aos moldes liberais. Constata-se a preocupação com a tutela concreta do indivíduo. Interessa ao Direito a proteção específica de componentes distintos da personalidade, capazes de torná-la único entre as demais.

Não se procurou de forma alguma a proteção da personalidade humana em abstrato, de modo a ser preenchida conforme concepções ideológicas distintas. É exatamente nessas bases e com essas preocupações que retornamos à nossa proposta de revisão da privacidade, com vistas a redesenhar o seu conteúdo, especialmente no que diz respeito à sua dimensão de autonomia decisória. Entretanto, como promover a privacidade individual para possibilitar o desenvolvimento da sua identidade?

É certo que o indivíduo real não se caracteriza como uma abstração. Ele convive em sociedade e dela assimila valores com os quais se identifica plenamente. Todavia, é igualmente certo que nem sempre seria possível uma correspondência plena entre os valores pessoais e os comunitários. Portanto, afirmar que o "indivíduo concreto" 
é resultante dos valores comunitários seria, no mínimo, temerário. Ao contrário, de acordo com o nosso entendimento, haveria uma necessidade de protegê-lo contra ingerências da comunidade, ainda que tais invasões desrespeitosas adviessem da convivência em grupos de libertação e movimentos sociais com os quais ele tivesse uma relação de pertinência.

Um caminho importante para a reflexão e garantia da autonomia decisória seria a reintrodução do direito ao corpo na temática da privacidade. Certamente, não na sua dimensão "individualistapossessivo", descrita por Macpherson (1979), como já mencionamos anteriormente, como se os nossos atributos pessoais, inclusive o próprio corpo, fossem propriedades individuais ou mercadorias a serem negociadas, mas, por exemplo, a partir das observações de Goffman (1971, p. 28), para quem o corpo constitui "um dos territórios de si".

Goffman (1971) entende que o sentimento de controle sobre o próprio corpo é essencial para uma percepção íntegra de si mesmo e para a autoconfiança. Consequentemente, o controle sobre o corpo é fundamental para a configuração da própria identidade e da dignidade pessoal.

Discutindo sobre a autonomia decisória mediada pelo corpo, Cohen (2012, p. 195) afirma: "nós somos nosso próprio corpo", e, ilustrando a importância do corpo para a individualidade, pontua: "não podemos escolher levá-los conosco por onde formos como o fazemos com nossas bolsas".

A questão da dignidade pessoal e da identidade ligadas ao controle do próprio corpo foi largamente utilizada pelas feministas para defender o direito ao aborto. Assim, afirmam: "nosso corpo, nós mesmas" (COHEN, 2012, p. 87). Não queremos esgotar o tema, mas apenas para o esclarecimento do que se vê aqui defendido, apresentaremos em breves linhas seus argumentos.

Para as feministas, afirmar a importância da integridade corporal, para efeitos de autonomia decisória, não é afirmar o direito de fazer 
com o próprio corpo o que se queira, como se ele fosse um direito de propriedade, aos moldes do individualismo-possessivo (MACPHERSON, 1979).

A questão central reside na defesa da individualidade e identidade femininas. Forçar uma mulher a uma gravidez indesejada implicaria em violar sua identidade corporal, impondo-lhe uma identidade de mulher grávida e de mãe. A experiência da gravidez constitui uma mudança substancial em sua identidade física e emocional, com reflexos de natureza econômica, promovendo alterações profundas em sua individualidade (COHEN, 2012). Vale lembrar que, em momento algum, esses argumentos buscam a defesa do aborto como um método anticonceptivo, mas colocar sob reflexão a importância da integridade corporal para a integridade da personalidade, considerando que a mulher não se restringe ao seu útero. De qualquer forma, é relevante ponderar que essa realidade, consoante a importância de que se reveste, somente poderia ser posta em segundo plano em face de um interesse estatal relevante ou de uma situação de risco significativo. A esse respeito, concordamos com Thomas (1992), para quem a privacidade é sempre mediada pelo próprio corpo, embora existam ainda outras dimensões presentes, como os recursos e os valores culturais disponíveis na comunidade (COHEN, 2012).

Daí a importância do termo embodiment, significativo da nossa corporificação, ou seja, o próprio corpo como o substrato mais relevante da identidade pessoal. Assim como ocorre com as outras dimensões da privacidade, a integridade corporal é necessária e fundamental para a autonomia decisória sobre si mesmo e, consequentemente, para sua identidade.

\section{Autonomia decisória: o direito de morrer com dignidade}

Até o presente momento, procuramos uma reflexão sobre a tutela da privacidade, buscando estabelecer um conteúdo mais apropriado às necessidades contemporâneas. Para tanto, retomamos as 
considerações sobre as suas dimensões: "o direito de ser deixado em paz" e a "autonomia decisória", identificando o controle sobre o próprio corpo como essencial à integridade e dignidade pessoal.

Certamente, se tais argumentos apontam a autonomia decisória sobre o próprio corpo - o embodiment, como forma de garantir uma vida plena em sua dignidade -, seria pertinente, neste momento, recolocarmos nossas reflexões sobre a própria morte, já que se trata de um momento significativo na vida de cada um.

Seria viável afirmar que a autonomia decisória sobre o próprio corpo remanesceria, mesmo diante da morte, como forma de conferir dignidade pessoal?

Enquanto as relações de saúde foram construídas sob uma ética paternalista, a autonomia decisória ficou prejudicada. Entretanto, o que se tem observado, em geral, é o abandono paulatino das teses paternalistas, com afirmação cada vez mais marcante da autonomia decisória enquanto poder de autodeterminação sobre o próprio corpo em questões atinentes à saúde. Esse movimento já é visível a partir do Relatório Belmont de 1978, apresentado pela National Comission for the Protection of Human Subjects of Biomedicals and a Behaviors Research, instituída pelo governo americano em 1974.

É bem verdade que o objetivo central do estudo em questão é identificar os princípios éticos básicos capazes de nortear a experimentação com seres humanos nas ciências do comportamento e na biomedicina (RIBEIRO, 2006). Entretanto, de qualquer maneira, premida ou não à ética médica, por necessidades outras que não a preocupação estrita com a autonomia decisória ou a integridade pessoal dos pacientes, o certo é que a autonomia foi identificada como princípio ético básico.

O princípio da autonomia, uma vez consagrado, constituiu um marco histórico nas transformações da ética médica paternalista, em prol do consentimento livre e esclarecido. Atualmente, denomina-se empowerment health, ou seja, o empoderamento do paciente sobre 
a sua saúde, transformando-o em titular de direito e o profissional da saúde em titular de uma obrigação (RIBEIRO, 2006).

Entretanto, a autonomia decisória implica em capacidade para a sua expressão, e há situações em que o paciente se torna incapaz de decidir. Nesses casos, poderíamos justificar o surgimento de testamentos vitais, instrumentos de manifestação de vontade para o futuro.

Essas questões podem ensejar caminhos de difícil solução, especialmente quando mesmo um testamento feito de próprio punho, por um indivíduo saudável ou no início de um processo de adoecimento, coloca-nos em situação de eventual invalidação de tal testamento quando o paciente adoeceu. É preciso que se considere a possibilidade de uma adaptação após um período de crise e uma mudança nas decisões quanto ao planejamento da própria morte. Como proceder nesses casos, quando o paciente já está impossibilitado de manifestarse?

Há ainda a situação das crianças que se encontram diante de problemas semelhantes. Poderiam elas manifestar validamente o seu desejo de viver ou morrer? Seus pais, os tutores, tomariam por elas essa decisão?

Para as questões levantadas, certamente não há uma solução consensual. Entretanto, é preciso não nos esquecer da presença de uma variável constante: os altos custos com os tratamentos médicos acabam pressionando pela opção menos onerosa, qual seja, a suspensão imediata destes.

3.1 Algumas considerações de ordem geral: distanásia, eutanásia e suicídio assistido

Diante da gravidade das questões que se apresentam, especialmente quando se está em presença da autonomia decisória como expressão da própria dignidade pessoal e do enfrentamento de decisões tão definitivas quanto viver ou morrer, algumas considerações de ordem geral parecem fundamentais para uma reflexão inicial. 
Em primeiro plano, como já pontuamos anteriormente, há a autonomia do paciente enquanto poder de autodeterminação, a fim de que ele possa participar e contribuir com os tratamentos médicos disponíveis. Entretanto, para ser realmente viável a privacidade decisória, deverá existir a informação necessária da equipe médica, de modo a esclarecê-lo, para que qualquer decisão tomada seja responsável (KOVÁCS, 2003). Tal situação só será possível, é claro, se houver simetria nas relações médico/paciente.

É importante considerar também a necessidade da informação de que, em muitas situações, não há caminhos suaves ou mesmo uma cura possível. Portanto, haverá conflitos entre as várias possibilidades de tratamento, com riscos distintos, os quais deverão ser ponderados na informação prestada.

Existirá, ainda, o risco velado de indução pelos caminhos menos onerosos em termos econômicos por parte dos hospitais ou dos sistemas privados de saúde, pressionando o profissional de medicina para que ele "aconselhe" ao paciente uma "escolha mais conveniente" para os hospitais ou sistema de saúde, ainda que talvez não tão interessante para o doente em questão. Nesses casos, estaríamos diante da violação da autonomia decisória, para além do código de ética profissional, embora seja de difícil comprovação.

Ainda nesse sentido, quando pensamos em autonomia decisória e no direito de morrer com dignidade, é preciso não esquecer os excluídos econômica e socialmente, que permanecem nas filas dos sistemas públicos de saúde aguardando uma oportunidade para o atendimento médico, muitas vezes com o comprometimento definitivo de sua saúde e o óbito consequente. Para esses casos, não há sequer eutanásia. É a realização pura e simples do extermínio, o que nos faz refletir sobre a honestidade dos argumentos morais, éticos e religiosos contrários à eutanásia quando desconectados do compromisso com essa realidade. 


\subsection{Distanásia}

Uma vez respeitada a autonomia decisória, vamos nos deparar com uma pluralidade de respostas para o processo de morrer na atualidade.

Entre elas, há a distanásia. Trata-se de vocábulo composto pelo prefixo dys, que significa "ato defeituoso", e thanatos, que significa morte. A distanásia é a morte lenta, com muito sofrimento, resultado de uma intervenção médica que se recusa a aceitar a dimensão da finitude da vida.

Esse caminho, por implicar em tratamento médico de alto custo, não constitui uma alternativa ou preocupação para a maioria da população. Entretanto, foi, de maneira recorrente, um procedimento adotado com pessoas de reconhecida expressão social, notadamente políticos, entre eles: Truman, Franco e Tancredo Neves (KOVÁCS, 2003).

A distanásia ocorre em instituições médicas extremamente bem aparelhadas, com instrumentos médicos sofisticados, capazes de promover o ressuscitamento, o que nos leva a indagar, diante do prolongamento de tanto sofrimento, até que ponto uma vida pode ser estendida?

Verifica-se, ainda, a presença dos "tratamentos fúteis", aqueles que não conseguem manter ou restaurar a vida nem promover o bemestar ou mesmo levar o paciente ao estado de consciência, seguindo o que ficou estabelecido pelo documento publicado pelo Hasting Center, em 1987, segundo o qual tais procedimentos só trariam sofrimentos adicionais.

Em que pese o reconhecimento do sofrimento inútil promovido pela distanásia, a questão central nessas situações é identificar, de forma acertada, até que ponto a utilização dos recursos médicos disponíveis tem utilidade, quando não para salvar o paciente, pelo menos para oferecer alívio ou controle dos sintomas (KOVÁCS, 2003).

A dificuldade em estabelecer os limites entre os tratamentos médicos obrigatórios (com alguma utilidade) e os absolutamente fúteis 
levou ao conceito do que atualmente conhecemos como tratamento proporcional para cada caso.

De qualquer forma, é importante entender que a suspensão eventual de um tratamento fútil não significa eutanásia nem abandono do doente, e sim a preocupação com a qualidade de vida do paciente e o respeito ao direito de morrer com dignidade.

\subsection{A eutanásia em suas diferentes modalidades}

Com a preocupação de colher esclarecimentos para uma possível reflexão, iremos nos reportar a Kaplan (2000). De acordo com o autor, teríamos a eutanásia ativa, que consistiria em uma ação concreta capaz de causar a morte ou acelerá-la. Haveria também a eutanásia passiva, a qual ocorreria sempre que houvesse a retirada dos procedimentos médicos capazes de promover a distensão da vida nos casos de impossibilidade de cura, cujo prolongamento do tratamento pudesse adicionar sofrimento ao paciente. Alguns autores não adotam essa terminologia, utilizando o termo "ortotanásia", que significa "morte na hora certa" (KOVÁCS, 2003).

Poderíamos mencionar, ainda, a eutanásia voluntária, que seria a ação causadora da morte a pedido do paciente, e, finalmente, a eutanásia involuntária, para a qual não haveria consentimento do paciente. Nesta, ocorreria o homicídio, possivelmente com atenuantes, se considerássemos a vontade de promover alívio ao sofrimento.

Em conexão com o tema, também vale mencionar o suicídio (ação capaz de provocar a própria morte), o suicídio passivo (que implicaria em sabotar o tratamento médico, como não ingerir os medicamentos prescritos) e o suicídio assistido (para os casos em que houvesse ajuda para realizá-lo). Do ponto de vista legal, esta ação estaria tipificada como crime.

\subsection{Eutanásia e o direito de morrer com dignidade}

A eutanásia, definida originalmente como a "boa morte", é um vocábulo derivado do grego. O prefixo eu significa "bom" e thanatos, 
morte. O termo acabou adquirindo uma nova dimensão, que seria a indução ou o apressamento do processo de morte (KOVÁCS, 2003).

É importante ressaltar que, conforme Kovács (2003), só haverá eutanásia se houver um pedido voluntário do paciente. A inexistência do pedido caracterizaria o assassinato ou a "morte roubada" (HENNEZEL, 2001), ainda que com a intenção de evitar o sofrimento para o paciente, para a sua família ou para os profissionais da medicina.

Os locais onde mais se pratica a chamada "morte roubada" são os hospitais, onde, para além do perigo de eventuais impulsos mortíferos de alguns profissionais, há também a preocupação em racionalizar custos. Como exemplo, temos os atuais casos de indução à morte, ocorridos no Hospital Evangélico de Curitiba, praticados, em grande parte, pela mesma profissional médica.

Uma alternativa que a nós pareceria pertinente e que merece reflexão é a legalização da eutanásia. Trata-se de proposta controvertida, objeto de intensos debates promovidos em todo mundo e que tem encontrado eco em países como a Holanda, onde, em 2002, houve uma mudança no seu ordenamento jurídico legalizando e regulando a eutanásia.

Entretanto, algumas dúvidas a respeito das consequências dessa legalização ainda não foram sanadas: ela poderia desviar a preocupação com a criação de programas de cuidados paliativos ao paciente, uma vez que a morte poderia ser o caminho mais fácil?

Não há garantias de que isso não possa ocorrer e certamente haverá sempre a pressão pela diminuição dos gastos com o tratamento. Também não se pode garantir que, para os casos de pessoas famosas, como os políticos no exercício do cargo, não seja ministrada a distanásia para acomodar eventuais necessidades de governo.

De qualquer forma, pensamos que a legalização da eutanásia, sob uma regulação capaz de oferecer parâmetros claros de comportamento, pode estabelecer limites de atuação aos profissionais da medicina, aos hospitais e aos sistemas de saúde (privados e públicos). 
Essas providências certamente não evitariam de maneira definitiva a "morte roubada" ou a distánasia, mas poderiam estabelecer regras de procedimento, sobretudo para garantir o exercício da autonomia decisória.

Outra questão constantemente levantada refere-se às pressões contrárias à legalização da eutanásia, originadas por convicções religiosas e igrejas constituídas.

A esse respeito, é preciso lembrar que, para além das crenças religiosas existentes na sociedade, as quais devem ser respeitadas e protegidas, o Estado é laico e a eutanásia não seria uma decisão imposta à sociedade. Significaria apenas uma possibilidade de autodeterminação e garantia do exercício da autonomia decisória, no que toca o direito de morrer com dignidade, tão somente para aqueles que dela quisessem fazer uso.

\section{Conclusão}

Quando nos ocupamos do direito de morrer com dignidade, deparamo-nos com uma pluralidade de caminhos disponíveis, devido ao avanço tecnológico da atualidade. Diante dessas possibilidades, fomos conduzidos a retomar a discussão sobre o conteúdo da privacidade e sua tutela constitucional em suas dimensões mais importantes, com vistas à proteção da autonomia decisória e dignidade pessoal.

Alvo de diferentes acusaçõese desconfianças, o direitoà privacidade é apontado, sobretudo, por reforçar um modelo idelógico liberal, fundado na dicotomia público/privado. De acordo com essas formulações, o direito à privacidade teria como meta central a proteção de indivíduos contra o Estado, o que reforçaria as tendências desagregadoras e atomizadoras da sociedade contemporânea, inviabilizando a afirmação dos valores comunitários, como a solidariedade.

Por outro lado, a privacidade positivada em termos liberais consistiria no reconhecimento de mais um direito individual, pelo qual 
se estaria buscando a tutela de um valor abstrato, atribuído ao indivíduo "natural", repleto do conteúdo ideológico burguês, que hsitoricamente serviu à exclusão e a dominação social.

Em que pesem as críticas apresentadas, procuramos estabelecer para a privacidade e sua tutela um substrato conceitual mais apropriado às necessidades contemporâneas, retomando seu conteúdo em duas dimensões: "o direito de ser deixado em paz" e a "autonomina decisória", identificando esta última com o controle do próprio corpo (embodiment), essencial à integridade física e à dignidade pessoal.

Certamente, os mesmos argumentos que apontavam a autonomia decisória sobre o próprio corpo como garantia de uma vida plena em dignidade pessoal nos levaram a refletir sobre sua importância diante da morte, já que se trata de um momento significativo na vida de cada um.

Diante da gravidade da questão apresentada, especialmente quando se trata de afirmar a autonomia decisória como expressão da própria dignidade pessoal e do enfrentamento de decisões tão cruciais quanto viver ou morrer, algumas considerações de ordem geral foram fundamentais para as nossas conclusões:

Em primeiro plano, a relevância da autonomia decisória do paciente, enquanto poder de autodeterminação, para que ele possa participar e contribuir com os tratamentos médicos disponíveis.

A necessidade da simetria nas relações entre médicos e pacientes, de modo a garantir a fruição das informações necessárias para esclarecêlo, contribuindo para a tomada de uma decisão responsável.

Para as questões atinentes à indução ou ao apressamento do processo de morrer (eutanásia), apontamos, novamente, a relevância da autonomia decisória do paciente como a única forma possível e necessária para a sua viabilização. Qualquer outra possibilidade caracterizaria assassinato ou "morte roubada".

Entendemos que a legalização da eutanásia, através de uma regulação responsável, pode oferecer parâmetros claros de um comportamento, estabelecendo limites de atuação aos profissionais 
da medicina, hospitais e sistemas de saúde (privados e públicos). Compreendemos, ainda, que a legalização não evitaria por completo as possibilidades da distanásia, "morte roubada" ou mesmo assassinatos, mas concluímos que, ao estabelecer regras de procedimento, estaríamos identificando os limites de comportamento, podendo, assim, garantir o exercício da autonomia decisória, necessária à dignidade pessoal.

\section{Referências}

ARENDT, Hannah. A origem do totalitarismo. São Paulo: Companhia das Letras, 1998.

BITTAR, C. A. Os direitos da personalidade. Rio de Janeiro: Forense, 1998.

BOBBIO, Noberto. Direito e Estado no pensamento de Emmanuel Kant. Brasília, DF: UNB, 1992.

COHEN, Jean L. Repensando a privacidade: autonomia, identidade e a controvérsia sobre o aborto. Revista Brasileira de Ciência Política, Brasília, DF, n. 7, p.165-203, abr. 2012.

GOFFMAN, Erving. The nature of deference and demeanor. In: INTERACTION ritual: essays on face-to-face behavior. New York: Pantheon, 1967. p. 473-502.

HENNEZEL, M. Nós não nos despedimos. Lisboa: Notícias, 2001.

KAPLAN, K.; BRATMAN, E. Gender, pain and doctor involvement: High school student attitudes toward doctor assisted suicide. Omega, Journal of Death and Dying, New York, v. 31, n. 3, p. 27-41, 2000.

KOVÁCS, M. J. Bioética nas questões da vida e da morte. Revista de Psicologia da USP, São Paulo, v. 14, n. 2, p. 115-167, 2003.

MACPHERSON, C. B. A teoria do individualismo possessivo. Rio de Janeiro: Paz e Terra, 1979.

RIBEIRO, D. C. Viver a própria morte e morrer a própria vida. Cadernos de Saúde Pública, Rio de Janeiro, v. 22, n. 8, p. 1749-1754, 2006. 
THOMAS, Kendall. Beyond the privacy principle. Columbia Law Review, Columbia, v. 92,

p. $1431-1516,1992$.

YOUNG, Iris. Justice and the politics of difference. Princeton: Princeton University Press, 1990.

Recebido em: 00/11/13

Aprovado em: 00/12/13 